\title{
MINDING THE GREENS: ROLE OF DIETARY SALICYLATES IN COMMON BEHAVIOURAL HEALTH CONDITIONS
}

\author{
S. MALAKAR ${ }^{a}$ and S. BhatTACHARYA ${ }^{b *}$ \\ ${ }^{a}$ Department of Gastroenterology, Central Clinical School, Monash University, \\ Level 6, The Alfred Centre, Melbourne, VIC 3004. Australia \\ bDeakin Graduate School of Business, Deakin University, \\ 221 Burwood Highway, Burwood, VIC 3125. Australia
}

(Received: 12 September 2013; accepted: 29 December 2013)

\begin{abstract}
The role of artificial food additives and food chemicals in abetting certain behavioural conditions has been the subject of behavioural nutrition research over several decades. However, a few studies have also raised questions regarding a similar role possibly played by naturally occurring phytochemicals in general and salicylates in particular. Such studies have, however, been rather few and far between. More importantly, till date, there has been no attempt to collate the findings from the few studies that have been carried out at different points in time by different researchers across different countries and cultures. This gap in the extant body of knowledge is made especially prominent by the fact that naturally occurring salicylates abound in many green vegetables and fruit, which are common constituents of a healthy diet. The aim of this review article is two-fold - firstly, to collate and present the related researches on the effects of salicylates in general and natural salicylates in particular on mental health; and secondly, to identify promising research directions for the future.
\end{abstract}

Keywords: naturally occurring salicylates, diet, ADHD, autism, depression, schizophrenia

\section{Background and motivation}

That diet can have an effect on physical as well as mental health is an idea that can be traced back to antiquity (Cosman, 1983; KanareK \& Orthen-Gambill, 1986). Ancient Egyptians believed that some foods had certain special "powers" over the human mind, e.g. salty foods were thought to stimulate passion, while onions were thought to have a calming effect and induce sleep (DARBY, 1977). In the classical Greek poem Odyssey, good and bad human traits were attributed to the type of food people consumed (FLint-HamiLton, 1999). Offerings to ancient Hellenic deities mainly consisted of meat and breads, while fruit and vegetables were thought not to possess the intrinsic qualities that could stimulate heroic acts and behaviour and were "considered beneath dignity of gods and heroes" (NESTLE, 1995). In ancient Indian medicine, different personality types were classified based among other things, on the components of one's diet, and eating habit was considered of vital importance to healthy life (MuKHERJEe, 2007). It was, however, only during the early decades of the twentieth century that physiologists started to investigate clinically the effects of diet on behavioural disorders. SHANNON (1922) formally hypothesized a role of certain dietary components on neuropathological manifestations in children. LENNOX and COBB (1928) for the first time scientifically studied the therapeutic effects of a ketogenic diet on the frequency and severity of epileptic

\footnotetext{
* To whom correspondence should be addressed.

Phone: +61 39244 6544; fax: +61 9244 5533; e-mail: sukanto@deakin.edu.au
} 
seizures. Later research along these lines has focused on the impact of diet components on several behavioural disorders, especially in children. However, while relevant literature is replete with studies of effects of diet on behavioural disorders ranging from autism to depression (SoH et al., 2009), there are surprisingly few reviews of research to date that investigated the association of a specific diet component with one or more of these disorders.

Methodologically speaking, the study of effects of diet on behaviour is not much dissimilar from a study of the effects of drugs/medications on behaviour. However, the former often has an added layer of complexity in terms of biochemically isolating the exact constituents of a diet. While in studies involving the effect of drugs on behaviour (usually applying some form of a dose-response model), one can be quite sure about the chemical characteristics of the drugs being administered as those can be satisfactorily 'homogenized', the same cannot always be done for all the components of a diet. Ideally, several levels of the target nutritional variable ought to be included in an experiment to correctly determine the true mathematical form of the dose-response curve. However, foods tend to contain many organic and inorganic constituents that may be naturally occurring or present as additives (e.g. naturally-occurring versus added sugars) and their respective detrimental psychophysical effects. MuRPHY and JoHnSON (2003) have argued that it is rather difficult to satisfactorily isolate the effects of natural versus added sugars, because even the so-called healthy diets that are largely based on fruit and vegetables do contain significant amounts of 'locked in' natural sugars (monosaccharides and disaccharides). Therefore, a complete and truly informative study of the effects of naturally-occurring versus added sugars would have to look at their comparative effects on psycho-physical health that, unfortunately, is nigh impossible in the absence of reliable data on the break-up of total sugar content between added and naturally-occurring for every single component of a particular diet (MURPHY \& JoHNSON, 2003).

Like sugars, there is another diet component that has also received some academic attention, especially in the past three or four decades, and these are the naturally-occurring salicylates. Salicylates are chemicals that occur naturally in many plants as a part of their internal defence against pests and diseases. So, we end up ingesting salicylates in their natural form (at varying levels) when we consume certain fruits, vegetables, and plant-derived foods. The benefits of a low-salicylate diet began to get identified a little over three decades ago and rigorous scientific research in this regard is still at a rather nascent stage. While most of the extant research on the effect of naturally-occurring salicylates is concentrated on the physiological manifestations of salicylate intolerance such as migraines, eczema, and irritable bowel syndrome, some researchers have also explored their role in behavioural disorders, especially in children, for example autism and the attention deficit hyperactivity disorder (ADHD) (Food Intolerance Network website). The study of salicylates in psycho-physical health has proven to be rather controversial and an especially difficult one to be targeted in clinical research because, unlike the other well-known 'nasties', e.g. fats and sugars, naturally-occurring salicylates are commonly found locked in a number of plant-derived foods that are normally considered essential ingredients of a healthy diet.

This paper is structured as follows: the next section gives a broad introduction to salicylates; the subsequent four sections each respectively review the literature on the effect of natural salicylates on ADHD, autism, schizophrenia, and depression; and then the concluding section sums up the article. In performing this review, the Google Scholar and PubMed databases were searched sequentially using the keywords diet, salicylates, behavioural disorders, ADHD, autism, schizophrenia, depression. 


\section{What are salicylates?}

Salicylic acid $\left[\mathrm{C}_{6} \mathrm{H}_{4}(\mathrm{OH}) \mathrm{COOH}\right]$ is a plant secondary metabolite primarily derived from trans-cinnamic acid and benzoic acid via the phenylpropanoid pathway and is a vital component of the plant's systemic acquired resistance system that enhances autonomic resistance to pathogen invasion (PATERSON et al., 2008). Aspirin ${ }^{\mathrm{TM}}$ (acetyl-salicylic acid) has been used pharmaceutically for over a century to treat localized pains and inflammations; and is obtained via esterification of the phenolic hydroxyl group of salicylic acid with the acetyl group from either of acetic anhydride or acetyl chloride (JEffreys, 2004). Pierpoint (2002) had also posited other likely roles of salicylates in plants, e.g. flowering stimulation, germination, and growth regulation. This might also explain the predominance of plant-based potions and remedies used in the olden days to treat pain and injuries. BosetTI and co-workers (2001) have also reported that regular intake of aspirin is associated with a decreased incidence of colon cancer. Many fruits, vegetables herbs, and spices used for human consumption contain natural salicylates mainly as salicylic acid and its various esters - so it has been suggested that the recognised effects of a diet composed largely of fruit and vegetables, on lowering bowel cancer risk, may at least partly be attributed to the presence of naturally occurring salicylates (PATERSON \& LAWRENCE, 2001). There is very little research that documents the natural salicylate contents of various food items in a typical modern Western diet; and to make matters more complicated, whatever little information is out there happens to be rather conflicting. Among the well-cited works in this regard, SwaIN and coworkers (1985), VENEMA and co-workers (1996), and PATERSON and co-workers (2006) have reported the content ( $\mathrm{mg} /$ kilogram) of natural salicylates in some common food items in a typical modern Western diet. A more exhaustive chart of food items with information on naturally occurring salicylate levels is freely downloadable from the popular site 'EVERYDAY WITH ADHD'.

While the beneficial effects of salicylate-rich foods (mainly fruits, vegetables, and other plant-derived products) in human diet have been extensively researched and documented, in recent years some attention has been drawn to some of the detrimental effects of salicylates on psycho-physical health. While dietitians and nutritionists throughout the developed world are advocating a diet rich in plant-based foods to combat increasing obesity and related ailments, especially amongst children and young adults, the research on the negative effects of naturally occurring salicylates has opened up the debate over the 'ideal' diet. It is against the above backdrop that a review of the current research on what we know of the role played by salicylates in general and naturally occurring salicylates in particular in some of the common behavioural disorders assumes relevance.

\section{Salicylates and attention deficit hyperactivity disorder (ADHD)}

Attention deficit hyperactivity disorder (ADHD) is the most common psychiatric disorder of childhood, affecting around $8 \%$ of US school-aged children aged between four and seventeen years, who exhibit the tell-tale signs of being inattentive, impulsive, and hyperactive and are often also affected by a host of other co-occurring psychological and learning disorders (STEvens et al., 2011). Although a variety of medical treatments and behavioural therapies exist for ADHD with fairly good prognosis, many parents are eager to explore alternative remedies to try and avoid the unwanted side effects of the former and the usually very long 
administration times of the latter. While the exact causes of ADHD are still unknown, symptoms are associated with dopaminergic and noradrenergic transmission, involving genetic as well as environmental factors (STEVENS et al., 2011).

FEINGOLD $(1973,1975)$ was the first to propose, somewhat controversially, that a likely environmental trigger of ADHD is the ingestion of certain foods/food additives to which subjects are hypersensitive. His proposition was mainly founded on his own clinical experiences treating aspirin-sensitive patients with behavioural problems (RoJAS \& CHAN, 2005). The famous Kaiser-Permanente (K-P) diet (later known as the Feingold program) was subsequently formulated that specifically labelled natural salicylates as one of the key foodrelated ADHD triggers. Since the original proposition by Feingold, there have been several experimental studies to test the efficacy of the K-P diet in treating ADHD-affected children (e.g. Conners et al., 1976; Harley et al., 1978; Kavale \& Forness, 1983; Gross et al., 1987). However, these studies did not specifically target natural salicylates in foods, rather testing for the efficacy of the K-P diet overall, which restricts ingestion of artificial food additives and preservatives along with consumption of some specific food items that contain natural salicylates, such as apples, oranges, berries, tomatoes, teas, and certain spices. Fitzsimon and co-workers (1978) first attempted to isolate the salicylate-specific effect on ADHD by studying the changes to triggered behavioural responses in hypersensitive children. But their study used a 40-mg purified acetyl-salicylic acid tablet (against a similar looking ascorbic acid placebo) instead of natural salicylate-containing food items. They found significant differences between the treatment and control subjects in terms of general cognitive capacity, line walking, and disturbance in normal sleep patterns. However, there are no such studies yet on the effect of natural salicylates in food.

The potential association of salicylate intake and ADHD was addressed in a comparative study of the nutritional pattern of school children with ADHD with that of normal children (Amani \& Khajeh Mougahi, 2005). Their study group was made up of four hundred schoolage children in a middle-eastern city where the parents and teachers completed the socioeconomic, anthropometric, and bio-behavioural scoring questionnaires specifically designed for this study. They failed to find any significant relationship between consumption of food rich in natural salicylates and degree and severity of ADHD. However, school-age boys who drank more than three cups of tea a day had a significantly increased severity of ADHD. However, although teas have high salicylate content, they also contain other phytochemicals, to which the test subjects may have been hypersensitive.

As can be deduced from a perusal of the extant literature, not a lot of research has happened as yet that attempts to clearly isolate the effect of natural salicylates in food items on the degree and severity of ADHD. 'Salicylate' is a rather general term that includes many compounds that contain the basic salicylate radical and the possible varieties include salicylic acid, sodium salicylate, methyl salicylate, and acetylsalicylic acid (GoODMAN and GiLman, 1965). The original K-P diet did not specify which of these varieties should be excluded or the intake levels at which they can trigger behavioural responses. The biggest roadblock to previous research in this regard seems to have been the paucity of reliable data on percentage content of various salicylates in specific food items (WENDER, 1986). Armed with an accurate chemical compositions database of common food items, researchers can look at setting up longitudinal studies using a structured sequence of elimination and challenge diets that can help reveal more clearly the causal effects, if any, of natural salicylates on severity of ADHD. CLARKE and co-workers (1996) have provided an elaborate schematic model of the critical steps that ought to be involved in a well-designed clinical investigation into pharmacological 
food intolerance. Similar models have already been widely used in investigating the effect of food additives and so it can be argued that they should also be helpful in investigating the effect of natural salicylates in food items. PERRY and co-workers (1996) also acknowledged that extant empirical evidence of a positive effect of salicylate-elimination diets in treatment of ADHD is at best weak and that further investigations are necessary. However, as yet, there does not appear to have been any study conducted that specifically singled out the effect of a reduced natural salicylate diet in the treatment of ADHD although there are several which have looked at the effect of a reduced artificial food colours and food additives diet. The therapeutic effect, if any, of a reduced natural salicylates diet on ADHD patients therefore continues to remain an open question to this day. Hence this provides a fertile area for future multi-disciplinary research that is likely to involve clinical dieticians, psychiatrists, and behaviour therapists.

\section{Salicylates and autism}

Autism (or autism spectrum disorder) is a developmental, cognitive disorder amongst children that mainly manifests as learning, communication, and behavioural impairment (FERNELL et al., 2007). It was again Feingold who first hypothesized and also provided some clinical evidence that salicylates "can produce in addition to hyperkinesis or MBD clinical patterns resembling those shown in a variety of neurologic disorders" including autism (Feingold, 1979). NeEds and Brooks (1985) noted that administering aspirin to children could put strain on their livers; which could then trigger a range of adverse physiological and behavioural responses. Hence, a variant of the K-P diet (later absorbed within the Feingold Program) was formulated for children suffering especially from the autism spectrum disorders. However, the efficacy of the K-P diet was challenged on the basis of clinical studies conducted under the aegis of important health institutions in the US like the American Council on Science and Health (Whelan et al., 1980) and the National Institutes of Health Consensus Development Conference Statement (NIH, 1982). However, Bernard Rimland, a noted autism expert of that time, came to the defence of the Feingold hypothesis and counterchallenged the scientific veracity of the clinical studies based on which the K-P diet was being attacked (RIMLAND, 1983). Several subsequent researchers have also provided support for the Feingold hypothesis, e.g. AlBERTI and co-workers (1999) observed that salicylates tend to have adverse biochemical effects in autistic children and can significantly worsen their disease symptoms. It has been conjectured that salicylates, being a subgroup of phenols, may be a contributory factor in worsening of symptoms in autistic patients who may have problems with breakdown of phenols (SRINIVASAN, 2009). Evidence has already been found that autistic patients tend to be deficient in a particular enzyme involved in metabolic breakdown of phenols and amines - phenol sulphur transferase or PST (WARING \& KLOVRZA, 2000).

Relatively recently, PATEL and CuRTIS (2007) reported that children with autism spectrum disorders responded better to multi-dimensional treatment strategies, which included a dietary intervention that restricted or eliminated refined sugar, chemical additives, salicylates, and also casein/gluten (if the patient was hypersensitive). However, although it favoured the Feingold hypothesis, as with the other dietary studies involving ADHD patients we cited in the previous section, this one too was not salicylate-specific. On the other hand, there are also some recent evidences that counter the original Feingold hypothesis. For example, EMOND and co-workers (2010) studied the comparative feeding habits, dietary patterns, and growth 
in infants with autism spectrum disorder against normal infants. The afflicted infants were found to consume less vegetable and fruit and also less of foods high in additives, e.g. sweets and aerated drinks. There were no significant differences with normal infants in terms of weight, height, or body mass index at eighteen months and eighty-four months age or in haemoglobin count at the latter age. However, the researchers do not clearly state whether the children afflicted with autism spectrum disorder ate less fruit and vegetable, etc. simply because they were given less of these food items to eat (e.g. because their parents were unable to afford these food items on a regular basis) or whether parents deliberately avoided giving these food items as they aggravated the symptoms. (If it was the latter then it could in fact go in favour of the original hypothesis of Feingold!) Good (2009) has further pointed out that although salicylates, whether ingested with food or administered as aspirin, may worsen the behavioural symptoms in already autistic children, there is no evidence indicating they can abet autistic regression in normal children.

Like with ADHD, the question of causality between low-salicylate diet and symptoms alleviation of autism spectrum disorders is still severely under-researched. The gap in the extant literature is even more prominent for salicylates present naturally in a number of fruits, vegetables, and plant-sourced food items - the common core ingredients of what one would likely consider to be a healthy diet. Given that it is now well-known that autistic patients tend to be PST-deficient, causal link between a low-salicylate diet and the mitigation of symptomseverity seems a rather plausible hypothesis. However, while the literature is replete with dietary intervention studies that look at artificial food additives, peer-reviewed studies focusing exclusively on the role of a diet low in salicylates in general and natural salicylates in particular in treating autism spectrum disorders are conspicuously absent.

\section{Salicylates and schizophrenia}

Schizophrenia is a chronic, severely disabling brain function disorder affecting approximately $1 \%$ of US population (US National Institute of Mental Health). There are behavioural as well as genetic causes that potentially underlie this affliction. DEAKIN and co-workers (1997) have observed that a genetic predisposition to schizophrenia is evidenced by significantly weakened frontal lobe function and that a loss of fronto-temporal projections leading to temporal lobe malfunction causes the manifest psychotic symptoms, which typically include severe delusions, episodic visual and/or auditory hallucinations, apathy, etc. The patients can become disorientated in their speech and general behaviour, which may be attributed to a stunted developmental process of synaptic elimination as they struggle to separate real world events, persons, and locations from the illusory ones. The condition can become debilitating to the extent that patients have to depend on others for their daily maintenance. While the psychotic symptoms can be largely managed with treatment regimes that are currently available, a permanent cure for this mental condition is still not at hand.

Using data obtained from Copenhagen Perinatal Cohort and from the Danish Psychiatric Central Register, SøRENSEN and co-workers (2004) found a statistically significant evidence of an elevated risk of schizophrenia from pre-natal exposure to aspirin (adjusted odds ratio $4.75,95 \%$ CI 1.9 to 12 ). When the relationship was causal, children born to mothers who took aspirin-like analgesics for a length of time that extended into the second trimester of the pregnancy would have an increased congenital risk of schizophrenia affliction. But what about the effect of natural salicylates present in the environment? Could they too have an 
impact on prognosis or treatment of schizophrenia affliction? Sørensen's results are perhaps suggestive that food salicylates would never be of sufficiently high quantity to affect normal people physiologically, but potential effect on salicylate-sensitive individuals remains unknown.

KING (1981) had argued that allergic reactions may have behavioural manifestations. In a double-blind experimental study, King exposed thirty test subjects to several allergens or to a placebo and found that behavioural changes were triggered in the presence of allergens but not in presence of the placebo. Although allergy symptoms are normally associated with physical disorders, GARFIELD (1985) conjectured that severe behavioural disorders like clinical depression and schizophrenia may also be abetted by allergies. Food items are one of the most common triggers for allergic reactions mediated via $\operatorname{IgE}$ antibodies and it is already well-known that some persons are hypersensitive to the salicylates contained in many food items - both natural as well as added. However, like ADHD and autism, the evidence so far of a positive role of low-salicylate diet in treatment of schizophrenia is largely anecdotal with a paucity of focused research.

PATERSON and co-workers (2006) conducted a study to investigate the beneficial effect of natural salicylates in preventing bowel cancer, for which they recruited a study group from village in southern India, where the diet principally consists of local vegetables, grains, and pulses seasoned with natural spices and herbs, and is mostly free of any artificial additives. What however rather interesting is that their study group consisted of exactly the same subjects who were recruited previously for another unrelated study that wanted to investigate the prevalence of dyskinesia among first-degree relatives of people diagnosed with schizophrenia (McCREADIE et al., 2003). The choice of subjects for their study group by McCreadie and co-workers was apparently influenced by the prevalence of cases of untreated schizophrenia amongst this particular rural population. This link has not been explored further and it merits further study.

MCCREADIE and co-workers (2005), however, carried out a study that could be seen to challenge the idea that natural salicylates in diet could worsen the symptoms of schizophrenia affliction. They hypothesized that people with schizophrenia make poor dietary choices, which leads to obesity and other health complications. They set up three 'treatments' - the first consisted of six months' supply of free fruits and vegetables along with instructions on planning a healthy diet, the second consisted of six months' supply of free fruits and vegetables but no instructions, and the third was 'status quo', i.e. the usual diets were continued. They randomly allocated these three 'treatments' among their test subjects. They found that after the intervention, those who received the first two 'treatments' were consuming significantly more fruits and vegetables than those in the 'status quo' treatment group. Consumption of fruits and vegetables was reported to fall to pre-intervention levels in a year after intervention stopped. However, they do not report any changes in the severity of the symptoms of the subjects who received either of the first two 'treatments', i.e. who were encouraged to move to a diet of fruits and vegetables - food items that tend to be typically quite rich in natural salicylates. It is not known whether they actually attempted to measure in any way the preand post-intervention severity levels of the symptoms, but it can be assumed that subjects did not exhibit any marked changes, which one would think, would then have been reported in their paper by the researchers.

More recent studies with pharmacological doses of aspirin have provided evidence for a beneficial effect on schizophrenic patients in reducing the severity of the symptoms (GrOHOL, 2010a). For example, a randomised placebo-controlled clinical trial found significant 
improvement in both Positive and Negative Syndrome Scale (PANSS) and psychotic scores with aspirin $1000 \mathrm{mg} /$ day than in the placebo-treated group (LAAN et al., 2010). However, a limiting factor was that the patients for this clinical trial were not selected on the basis of salicylate hypersensitivity. Nevertheless, whether a similar positive effect could be also demonstrated via food-based salicylates, still remains to be tested.

That diet can have an impact on patients with schizophrenia affliction is well addressed in the extant literature. For example, a causal relationship between gluten ingestion and severity of schizophrenic symptoms was posited by DoHAn (1966). More recently, a lessening of the severity of psychotic symptoms of schizophrenia has been reported following a move to a low-carbohydrate, ketogenic diet, where the possible reasons were surmised to be gluten elimination (for gluten-hypersensitive patients) and "modulation of the disease of schizophrenia at the cellular level” (KRAFt \& Westman, 2009). Reichelt and GARDNER (2012) have corroborated this and have claimed that dietary intervention can prove helpful for some schizophrenia sufferers - an area which they acknowledge as being rather under-researched. Therefore, methodologically similar studies investigating the effect of a low-salicylate diet on schizophrenia are quite plausible and are strongly warranted given the somewhat conflicting landscape revealed by the aspirin studies of SøRENSEN and co-workers (2004) and LAAN and co-workers (2010).

\section{Salicylates and depression}

In a normally functioning human brain, the major mood-regulating neurotransmitters like dopamine, serotonin, and noradrenaline interact with a sequence of neurons without any depletion of signal strength from the first to the second to the subsequent neurons. When afflicted with depression, however, these neurotransmitters lose their normal functioning, so that the signal is depleted when passed on from one neuron to the next. Aetiologically, depressive disorders have a roughly 60-40 split between environmental triggers and genetic predisposition. Other factors are: gender - with women more likely than men to suffer the 'non-melancholic' type of depression (i.e. more psychological than physiological in its origin), aging - with diminishing brain function, side-effects of diseases - e.g. certain cancers, and personality factors - e.g. psychopathological differences (Black Dog Institute website).

In this review, we are particularly focusing on 'clinical depression', which is one of the most commonly diagnosed forms (Solomon et al., 2010). Several studies have attempted to understand the relation between dietary components and clinical depression. Much attention has been paid to the fatty acid content of the diet with variable results (HibBeln \& SALEM, 1995; Edwards et al., 1998; LuCAS et al., 2011; SÁnChEZ-Villegas et al., 2011). Little attention, however, has been paid to dietary salicylates. Indirect potential involvement of salicylates in clinical depression derives from the observation that free tryptophan in plasma is a significant factor in the turnover of some mood-regulating neurotransmitters like serotonin under normal and disease conditions. This might explain any mood-related side effect of aspirin that displaces bound tryptophan (PAoletTI et al., 1975). Actual dietary studies specifically to examine the effect of low salicylate-diets on clinical depression are again extremely rare. Dengate (2009) talks of a patient who was suffering from major depressive episodes and was not responding to medication. Four weeks after being put on an elimination diet prepared by the Royal Prince Alfred Hospital (RPAH) Allergy Clinic at Sydney, Australia, his mood improved remarkably and also the depressive episodes along with other 
psychological symptoms were greatly diminished. This special diet eliminates approximately fifty artificial additives in food and medicines as well as naturally occurring salicylates. While this patient was actually found to be allergic to some of the artificial additives, it is plausible that patients afflicted with clinical depression who are salicylate-hypersensitive may respond similarly. This particular case was earlier published as a clinical study (PARKER \& WATKINS, 2002), wherein the researchers had concluded that food intolerance could be a contributing factor in major depressive disorders that must be taken into consideration before prescribing anti-depressant medication or preparing a treatment regimen. Also there is empirical evidence, which suggests that individuals (especially females) who had developed ADHD as children have a significantly higher likelihood of developing clinical depression as adults (FARAone, 2006; Biederman et al., 2006, 2010; Grohol, 2010b). This implicates salicylates in at least an indirect involvement - as a trigger for ADHD symptoms in children, who then have a stronger predisposition to develop clinical depression when they grow up.

WALKER and co-workers (2008) has reported that patients of inflammatory bowel disease (IBD) have a significantly higher long-term risk of developing clinical depression compared to normal population. MosCANDREw and co-workers (2009) have also corroborated that clinicians must be aware of the high co-morbidity risk of IBD patients suffering from depression while screening them for the state of the disease and also while implementing a specific treatment regime. Interestingly, it is also quite well-known that many IBD patients are salicylate-hypersensitive, clearly evidenced by their poor response to aspirin administration as an anti-inflammatory drug (DAVIES, 1995; RoBInson et al., 1995). So, a latent link between salicylic acid (and its compounds) and clinical depression is plausible and poses an interesting research problem begging a deeper inquiry.

While there are some indirect implications for a possible role of salicylates as a contributing/exacerbating factor in clinical depression, no compelling evidence has been seen as yet. HAMDAN (2008) has observed that high blood concentrations of salicylates can cause delirium and other psychotic episodes; so this may be seen to abet manic-depressive types of behaviour; but this is again in a toxico-pharmacological rather than a dietary context. There are no studies yet that show whether at all, and if so, then at what levels can the intake of salicylate-rich foods trigger depression.

\section{Conclusion: what the current landscape looks like - implications for mental health}

It is quite apparent from the above discussions that Feingold hypothesis is still the central theoretical edifice when it comes to explaining the possible role of salicylates in several behavioural disorders. However, the Feingold hypothesis, even after more than three decades, continues to be controversial with no definite evidence to either unconditionally accept or reject the same. ADHD is clearly the behavioural disorder that has been at the focal point of most clinical research into the effectiveness of the Feingold program as a therapeutic dietary regimen. However, studies that have specifically tried to isolate the effect of salicylates (which is only one of the several elimination items in a typical Feingold diet) are few, and in those the effect of naturally occurring salicylates in common food items has not been studied. Rather, the preference has been to concentrate on dose-response behaviour of the pharmacological forms and doses of the compound. But what the current landscape does reveal are some interesting questions/problems that should spur future inter-disciplinary 
research with a potential to unearth crucial latent facts and links. Some of the open questions that have been uncovered through this review are highlighted below:

(i) What are the therapeutic effects, if any, on ADHD-afflicted children of a diet that specifically eliminates salicylates?

(ii) Given that autism patients tend to be PST-deficient, can salicylates elimination lead to a significantly better prognosis?

(iii) Whether, and if so, then why does a specific, closed population with a vegetarian diet consisting of food items rich in natural salicylates have a significantly higher incidence of schizophrenia?

(iv) How does one reconcile the conflicting evidence on the role of salicylates in schizophrenia as reported by SøRENSEN et al. (2004) and LANN and co-workers (2010)?

(v) Given that some IBD patients can be salicylate-hypersensitive and clinical depression has a significantly high co-morbidity risk with IBD, can a low-salicylates diet help in clinical depression?

Major limitations for assessing the effect of dietary salicylates include, first and foremost, the huge variance of reporting of salicylate content of foods. Such reporting is essential, since dose appears to be very important in salicylate-mediated effects. Pharmacological doses would seem unlikely to be achieved by dietary salicylates. Secondly, it is not yet clearly established wether or not all forms of salicylates (including plant derived ones) have a similar end effect from a pharmacological perspective. Thirdly, low-salicylates diets tend to be less flavoursome and palatable. Since compliance with dietary regimens is important for efficacy of a diet, this provides an unwanted added difficulty. Compliance typically needs more than simply finding a least-cost diet plan that meets the recommended nutritional requirements diets also need to be matched with patients' 'coping skills' and metabolic types (BROwNELL \& Cohen, 1995; Adams et al., 2011; NABIN et al., 2013). As has been noted as our major motivation for this work, natural salicylates occur mostly in food items that typically are included in 'healthy' (e.g. low-fat, low-sucrose, low-sodium, etc.) diets. Therefore, formulation of a range of low-salicylate diets that also have low 'drop-out' rates is likely to prove challenging and therefore stimulate further productive research into these areas as well. This is made more difficult by the fact that a diet low in natural salicylates is likely to be deficient in some of the essential ingredients of an otherwise healthy diet. The formulation of an optimal low-salicylate diet that is not nutritionally deficient, palatable as well as economical to comply with on a day-to-day basis is a particularly testing problem, especially in the absence of more concrete, conflict-free information on the salicylate content of various food items. Moreover, it is only after a causal link has been empirically established between dietary intake levels of salicylates and the risk of exacerbated symptom severity for behavioural disorders, that one can then look at the other related problem areas, e.g. formulation of alternative diets and ensuring better compliance to dietary regimen. Very recently, a paper published in the Medical Journal of Australia (GRAY et al., 2013) has opened the Pandora's Box on the entire issue of clinical efficacy of low-salicylate diets, stirring up a huge debate and, unfortunately, more conflicting viewpoints. The open questions as listed above and the extant literature from which these have been mined, do nevertheless suggest a potentially rich multi-disciplinary research area that is hitherto largely unexplored. There is a present and urgent need for both broader as well as deeper investigations that would academically inform the pertinent disciplines and improve the current state of clinical practice, especially when advocating typical 'healthy' eating plans. 


\section{References}

Adams, J.B., Audhya, T., McDonough-Means, S., Rubin, R.A., Quig, D., Geis, E., Gehn, E., Loresto, M., Mitchell, J., Atwood, S., Barnhouse, S. \& Lee, W. (2011): Nutritional and metabolic status of children with autism vs. neurotypical children, and the association with autism severity. Nutr. \& Metab., 8, 34.

Alberti, A., Pirrone, P., Elia, M., Waring, R.H. \& Romano, C. (1999): Sulphation deficit in "low-functioning" autistic children: a pilot study. Biol. Psychiat., 46, 420-424.

Amani, R. \& Khajeh Mougahi, N. (2005): Comparison between nutritional pattern of school children with attention deficit hyperactivity disorder and that of normal subjects. J. Iran Univ. Medical Sci., 12, 37-42.

Biederman, J., Petty, C.R., Monuteaux, M.C., Fried, R., Byrne, D., Mirto, T., Spencer, T., Wilens, T.E. \& Faraone, S.V. (2010): Adult psychiatric outcomes of girls with attention deficit hyperactivity disorder: 11-year followup in a longitudinal case-control study. Am. J. Psychiat., 167, 409-417.

Biederman, J.M., Spencer, T.J., Monuteaux, M.C. \& Faraone, S.V. (2006): Young adult outcome of attention deficit hyperactivity disorder: a controlled 10-year follow-up study. Psychol. Med., 36, 167-179.

Black Dog Institute, www.blackdoginstitute.org.au/docs/causesofdepression.pdf (last accessed October 31, 2013).

Bosetti, C., Gallus, S. \& La Vecchia, C. (2001): Aspirin and cancer risk: an update to 2001. Eur. J. Cancer Prev., $11,535-542$.

Brownell, K.D. \& Cohen, L.R. (1995): Adherence to dietary regimens. 2: Components of effective interventions. Behav. Med., 20, 155-164.

Conners, C.K., Goyette, C.H., Southwick, D.A., Lees, J.M. \& Andrulonis, P.A. (1976): Food additives and hyperkinesis: A controlled double-blind experiment. Pediatrics, 58, 154-166.

Cosman, M.P. (1983): A feast for Aesculapius: historical diets for asthma and sexual pleasure. Ann. Rev. Nutr., 3, $1-33$.

Clarke, L., McQueen, J., Samild, A. \& Swain, A. (1996): The dietary management of food allergy and food intolerance in children and adults. Aust. J. Nutr. Dietetics, 53, 89-98.

DArby, W.J. (1977): Food: The gift of Osiris. Plenum Press, New York, USA. 900 pages.

DAvies, N.M. (1995): Clinical pharmacokinetics of flurbiprofen and its enantiomers. Clin. Pharmacokinet., 28, 100114.

Deakin, J.F., Simpson, M.D., Slater, P. \& Hellewell, J.S. (1997): Familial and developmental abnormalities of front lobe function and neurochemistry in schizophrenia. J. Psychopharm., 11, 133-142.

Dengate, C. (2009): Food and depression. Australian Certified Organic Magazine, Autumn 2009, $22-23$.

Dohan, F.C. (1966): Cereals and schizophrenia data and hypothesis. Acta Psychiat. Scand., 42, 125-152.

Edwards, R., Peet, M., Shay, J. \& Horrobin, D. (1998): Omega-3 polyunsaturated fatty acid levels in the diet and in red blood cell membranes of depressed patients. J. Affect. Disorders, 48(2-3), 149-155.

Emond, A., Emmett, P., Steer, C. \& Golding, J. (2010): Autism spectrum disorders feeding symptoms, dietary patterns, and growth in young children with autism spectrum disorders. Pediatrics, 126(2), 337-342.

Everyday with adhd and challenging behaviours, www.everydaywithadhd.com.au/ (last accessed October 31, 2013).

FARAONE, S.V. (2006): The age-dependent decline of attention deficit hyperactivity disorder: a meta-analysis of follow-up studies. Psychol. Med., 36, 159-165.

FeIngOLd, B.F. (1973): Hyperkinesis and learning difficulties linked with the ingestion of artificial flavors and colors. -in: AMA Section on Allergy, Atlantic City, NJ, USA, June 24, 1973.

FeIngold, B.F. (1975): Hyperkinesis and learning disabilities linked to artificial food flavors and colors. Am. $J$. Nursing, 75, 797-803.

FeIngold, B.F. (1979): Dietary management of nystagmus. J. Neural Transm., 45, 107-115.

Fernell, E., Karagiannakis, A., Edman, G., Bjerkenstedt, L., Wiesel, F.A. \& Venizelos, N. (2007): Aberrant amino acid transport in fibroblasts from children with autism. Neurosci. Lett., 418, 82-86.

Fitzsimon, M., Holborow, P., Berry, P. \& Latham, S. (1978): Salicylate sensitivity in children reported to respond to salicylate exclusion. Med. J. Aust., 2, 570-572.

Flint-Hamilton, K.B. (1999): Legumes in ancient Greece and Rome: Food, medicine, or poison? Hesperia, 68, 371-385.

FOOD INTOLERANCE NETWORK, http://fedup.com.au/factsheets/overview (last accessed October 31, 2013).

Garfield, E. (1985): Allergies are nothing to sneeze at. Part 3 Behavioral manifestations. Essays of an Information Scientist, 8, 392-402.

Good, P. (2009): Did acetaminophen provoke the autism epidemic? Alternative Medicine Rev., 14, 364-372.

Goodman, L.S. \& Gilman, A. (1965): The pharmacological basis of therapeutics. Macmillan, New York, USA, 1785 pages. 
Gray, P.E., Mehr, S., Katelaris, C.H., Wainstein, B.K., Star, A., Campbell, D., Joshi, P., Wong, M., Frankum, B., Keat, K., Dunne, G., Dennison, B., Kakakios, A. \& Ziegler, J.B. (2013): Salicylate elimination diets in children: is food restriction supported by the evidence? Med. J.Australia, 198(11), 600-602.

Groноl, J. (2010a): Aspirin for schizophrenia? Available at: Psych Central, http://psychcentral.com/blog/ archives/2010/05/27/aspirin-for-schizophrenia/ (last accessed October 31, 2013).

Gronol, J. (2010b): What do girls with ADHD look like as adults? Available at: Psych Central, http://psychcentral. com/blog/archives/2010/02/18/what-do-girls-with-adhd-look-like-as-adults/ (last accessed October 31, 2013).

Gross, M.D., Tofanelli, R.A., Butzirus, S.M. \& Snodgrass, E.W. (1987): The effect of diets rich in and free from additives on the behavior of children with hyperkinetic and learning disorders. J. Am. Acad. Child Psy., 26, 53-55.

Hamdan, T.A. (2008): Psychiatric aspects of orthopaedics. J. Am. Acad. Orth. Surgeons, 16, 41-46.

Harley, J.P., Ray, R.S., Tomasi, L., Eichman, P.L., Matthews, C.G., Chun, R., Cleeland, C.S. \& Traisman, E. (1978): Hyperkinesis and food additives: testing the Feingold hypothesis. Pediatrics, 61, 818-828.

Hibbeln, J.R. \& SAlem, N. (1995): Dietary polyunsaturated fatty acids and depression: when cholesterol does not satisfy. Am. J. Clin. Nutr., 62(1), 1-9.

JefFreys, D. (2004): Aspirin: The story of a wonder drug. Bloomsbury Publishing, London, UK. 352 pages.

Kanarek, R.B. \& Orthen-Gambill, N. (1986): Complex interactions affecting nutrition-behavior research. Nutr. Rev., 44, 172-175.

KaVAle, K.A. \& Forness, S.R. (1983): Hyperactivity and diet treatment: a meta-analysis of the Feingold hypothesis. J. Learn. Disabil., 16, 324-330.

KING, D.S. (1981): Can allergic exposure provoke psychological symptoms? Biol. Psychiat., 16, 3-19.

Kraft, B.D. \& WeStMAn, E.C. (2009): Schizophrenia, gluten and low carbohydrate, ketogenic diets: a case report and review of the literature. Nutr. Metab., 6(10), 1-3.

Laan, W., Grobbee, D.E., Selten, J-P., Heijnen, C.J., Kahn, R.S. \& Burger, H. (2010): Adjuvant aspirin therapy reduces symptoms of schizophrenia spectrum disorders: results from a randomized, double-blind, placebocontrolled trial. J. Clin Psychiat., 71, 520-527.

Lennox, W.G. \& CobB, S. (1928): Studies in epilepsy. VIII: The clinical effect of fasting. Arch. Neurol. Psychiat., 20, 771-779.

Lucas, M., Mirzaei, F., O’reilly, E.J., Pan, A., Willett, W.C., Kawachi, I., Koenen, K. \& Ascherio, A. (2011): Dietary intake of n-3 and n-6 fatty acids and the risk of clinical depression in women: a 10-y prospective follow-up study. Am. J. Clin. Nutr., 93, 1337-1343.

McCreadie, R.G., Kelly, C., Connolly, M., Williams, S., Baxter, G., Lean, M. \& Paterson, J.R. (2005): Dietary improvement in people with schizophrenia. Brit. J. Psychiat., 187, 346-351.

McCreadie, R.G., Thara, R., Srinivasan, T.N. \& Padmavathi, R. (2003): Spontaneous dyskinesia in first-degree relatives of chronically ill, never-treated people with schizophrenia. Brit. J. Psychiat., 183, 45-49.

Moscandrew, M., Mahadevan, U. \& Kane, S. (2009): General health maintenance in IBD. Inflamm. Bowel Dis., 15, 1399-1409.

MukherJee, R. (2007): Concept of personality type in West and in Ayurveda. Indian J. Traditional Knowledge, 6, $432-438$.

Murphy, S.P. \& Johnson, R.K. (2003): The scientific basis of recent US guidance on sugars intake. Am. J. Clin. Nutr., 78, 827-833.

Nabin, M.H., Kumar, K. \& Bhattacharya, S. (2013): Optimal diet selection and the compliance problem: A technical note. J. Interdiscipl. Math., 16, 83-95.

National institute of mental health, www.nimh.nih.gov/health/publications/schizophrenia/schizophrenia-booket2009.pdf (last accessed October 31, 2013).

Needs, C.J. \& Brooks, P.M. (1985): Clinical pharmacokinetics of the salicylates. Clin. Pharmacokinet., 10, 164177.

Nestle, M. (1995): Mediterranean diets: historical and research overview. Am. J. Clin. Nutr., 61, 1313-1320.

NIH (1982): Consensus Development Conference Statement, http://consensus.nih.gov/1982/1982Biomaterials034h tml.htm (last accessed 29. December 2013)

Paoletti, R., Sirtori, C.J.R. \& Spano, P.F. (1975): Clinical relevance of drugs affecting tryptophan transport. Annu. Rev. Pharmacol., 15, 73-81.

PARker, G. \& Watkins, T. (2002): Treatment-resistant depression: when antidepressant drug intolerance may indicate food intolerance. Aust. NZ. J. Psychiat, 36, 263-265. 
PAtel, K. \& CurTis, L.T. (2007): A comprehensive approach to treating autism and attention-deficit hyperactivity disorder: A prepilot study. J. Altern. Complem. Med., 13, 1091-1097.

Paterson, J.R., Baxter, G., Dreyer, J.S., Halket, J.M., Flynn, R. \& Lawrence, J.R. (2008): Salicylic acid sans aspirin in animals and man: persistence in fasting and biosynthesis from benzoic acid. J. Agric. Fd Chem., 56, $11648-11652$.

Paterson, J.R. \& Lawrence, J.R. (2001): Salicylic acid: a link between aspirin, diet and the prevention of colorectal cancer. Q. J. Med., 94, 445-448.

Paterson, J.R., Srivastava, R., Baxter, G.J., Graham, A.B. \& Lawrence, J.R. (2006): Salicylic acid content of spices and its implications. J. Agric. Fd Chem., 54, 2891-2896.

Perry, C.A., Dwyer, J., Jeffrey, A., Gelfand, M.D., Couris, R.R. \& McCloskey, W. (1996): Health effects of salicylates in foods and drugs. Nutr. Rev., 54, 225-240.

Pierpoint, W.S. (2002): Can aspirin help identify leaf proteins active in defence responses? Ann. Appl. Biol., 140, 233-239.

Reichelt, K.L. \& Gardner, M.L.G. (2012): Genetic and dietary factors related to schizophrenia. Open J. Psychiat., $2,12-20$.

Rimland, B. (1983): The Feingold diet: An assessment of the reviews by Mattes, by Kavale and Forness and others. J. Learn. Disabil., 16, 331-333.

Robinson, M.H., Wheatley, T. \& Leach, I.H. (1995): Non-steroidal anti-inflammatory drug-induced colonic stricture: An unusual cause of large bowel obstruction and perforation. Digest. Dis. Sci., 40, 315-319.

RojAS, N.L. \& CHAN, E. (2005): Old and new controversies in the alternative treatment of attention-deficit hyperactivity disorder. Ment. Retard. Dev. D. R., 11, 116-130.

Sánchez-Villegas, A., Verberne, L., De Irala, J., Ruíz-Canela, M., Toledo, E., Serra-Majem, L. \& MartínezGonzÁLEZ, M.A. (2011): Dietary fat intake and the risk of depression: the SUN Project. PLoS ONE, 6(1), 16268.

SHANNON, W.R. (1922): Neuropathologic manifestations in infants and children as a result of anaphylactic reaction to foods contained in their diet. Am. J. Dis. Child., 24, 89-94.

Soh, N., Walter, G., Baur, L. \& Collins, C. (2009): Nutrition, mood and behaviour: a review. Acta Neuropsychiatr., $21,214-227$.

Solomon, J.A., Zukier, Z. \& Hamadeh, M.J. (2010): Minding our bodies. Available at: http://www.mindingourbodies. ca/about the_project/literature_reviews/depression_and_nutrition (last accessed October 31, 2013).

Sørensen, H.J., Mortensen, E.L., Reinisch, J.M. \& Mednick, S.A. (2004): Association between prenatal exposure to analgesics and risk of schizophrenia. Brit. J. Psychiat., 185, 366-371.

Srinivasan, P. (2009): A review of dietary interventions in autism. Ann. Clin. Psychiat., 21, 237-247.

Stevens, L.J., Kuczek, T., Burgess, J.R., Hurt, E. \& Arnold, L.E. (2011): Dietary sensitivities and ADHD symptoms: Thirty-five years of research. Clin. Pediatr., 50, 279-293.

Swain, A.R., Dutton, S.P. \& Truswell, A.S. (1985): Salicylates in foods. J. Am. Diet. Assoc., 85, 950-960.

Venema, D.P., Hollman, P.C.H., Janssen, P.L.T.M.K. \& Katan, M.B. (1996): Determination of acetylsalicylic and salicylic acid in foods using HPLC with fluorescence detection. J. Agric. Fd Chem., 44, 1762-1767.

Walker, J.R., Ediger, J.P., Graff, L.A., Greenfeld, J.M., Clara, I., Lix, L., Rawsthorne, P., Miller, N., Rogala, L., McPhail, C.M. \& Bernstein, C.N. (2008): The Manitoba IBD cohort study: a population-based study of the prevalence of lifetime and 12-month anxiety and mood disorders. Am. J. Gastroenterol., 103, 1989-1997.

Waring, R.H. \& Klovrza, L.V. (2000): Sulphur metabolism in autism. J. Nutr. Environ. Med., 10, $25-32$.

Wender, E.H. (1986): The food additive-free diet in the treatment of behavior disorders: A review. Dev. Behav. Pediatr., 7, 35-43.

Whelan, E.M., Stare, F.J. \& Sheridan, M. (1980): Diet and hyperactivity: Is there a relationship? Pediatrics, 66, $521-525$. 